\title{
Atividade de enzimas antioxidantes e inibição do crescimento radicular de feijão caupi sob diferentes níveis de salinidade
}

Josemir Moura Maia ${ }^{1,4}$, Sérgio Luiz Ferreira-Silva ${ }^{2}$, Eduardo Luiz Voigt ${ }^{1}$, Cristiane Elizabeth Costa de Macêdo ${ }^{1}$, Luiz Ferreira Aguiar Ponte ${ }^{3}$ e Joaquim Albenisio Gomes Silveira ${ }^{2}$

Recebido em 8/02/2010. Aceito em 16/02/2012

\section{RESUMO}

(Atividade de enzimas antioxidantes e inibição do crescimento radicular de feijão caupi sob diferentes níveis de salinidade). A peroxidase de fenóis (POX) é uma enzima que associa a remoção do peróxido de hidrogênio com a biossíntese de lignina, contribuindo para a inibição do crescimento pelo espessamento da parede secundária. Com o objetivo de verificar as relações entre a inibição do crescimento e a modulação oxidativa induzida por estresse salino, foram avaliadas as atividades das enzimas dismutase do superóxido (SOD), catalase (CAT), peroxidase de ascorbato (APX) e POX em raízes de feijão caupi sob salinidade. Plântulas das cultivares Pitiúba e Pérola com quatro dias foram expostas ao $\mathrm{NaCl}$ 0, 25, 50, 75 e $100 \mathrm{mM}$ em papel de germinação sob condições controladas. Após dois dias de tratamento, o comprimento radicular foi reduzido pelo $\mathrm{NaCl} 100 \mathrm{mM}$ em $56 \mathrm{e}$ $26 \%$ nas cultivares Pitiúba e Pérola, respectivamente, associado ao aumento do vazamento de eletrólitos e à morte celular no ápice radicular. A salinidade não causou aumento da peroxidação de lipídios nas raízes, indicando que a morte celular se deve mais a danos nas membranas do que ao estresse oxidativo. O estresse salino reduziu a atividade das enzimas SOD, CAT e APX e causou intenso aumento da atividade de POX, demonstrando que essa última exerce algum papel na proteção oxidativa das raízes sob salinidade. Em conclusão, a redução no alongamento das raízes de feijão caupi sob salinidade pode ser atribuída, pelo menos em parte, a uma sincronia entre o aumento da atividade de peroxidase de fenóis e redução nas atividades de catalase e peroxidase de ascorbato.

Palavras-chave: Crescimento radicular, estresse salino, proteção oxidativa, Vigna unguiculata

\begin{abstract}
(Activities of antioxidant enzymes and root growth inhibition in cowpea seedlings exposed to different salt levels). Phenol peroxidase (POX) is a dual enzyme that is involved with hydrogen peroxide scavenging and lignin biosynthesis, contributing to growth inhibition by secondary wall thickening. In order to relate growth inhibition to salt-induced oxidative modulation, the activities of superoxide dismutase (SOD), catalase (CAT), ascorbate peroxidase (APX) and POX were evaluated in cowpea roots under salinity. Four-day-old seedlings of the Pitiúba and Pérola cultivars were exposed to $0,25,50,75$ and $100 \mathrm{mM} \mathrm{NaCl}$ in germination paper under controlled conditions. After two days of treatment, root length was reduced under $100 \mathrm{mM} \mathrm{NaCl}$ by 56 and $26 \%$ in Pitiúba and Pérola, respectively, which was associated with enhanced electrolyte leakage and cell death in the root apex. $\mathrm{NaCl}$ salinity did not trigger lipid peroxidation, indicating that cell death was probably due to membrane damage instead of oxidative stress. Salt stress reduced the activity of SOD, CAT and APX and increased the POX activity, demonstrating that this enzyme plays a role in oxidative protection in cowpea roots exposed to $\mathrm{NaCl}$ salinity. In conclusion, salt-induced growth inhibition in cowpea roots could be attributed, at least in part, to a coordinate action involving an increase in POX activity and a drop in CAT and APX activities.
\end{abstract}

Key words: Oxidative protection, root growth, salt stress, Vigna unguiculata

1 Universidade Federal do Rio Grande do Norte, Centro de Biociências, Departamento de Biologia Celular e Genética, Laboratório de Estudos em Biotecnologia Vegetal, Natal, RN, Brasil

2 Universidade Federal do Ceará, Departamento de Bioquímica e Biologia Molecular, Laboratório de Metabolismo de Plantas, Campus do Pici, Fortaleza, CE, Brasil

3 Universidade Estadual Vale do Acaraú, Campus da Betânia, Sobral, CE, Brasil

4 Autor para correspondência: jmouram@yahoo.com.br 


\section{Introdução}

A salinidade é um dos principais fatores ambientais que afeta o rendimento das culturas em diversas regiões do mundo, particularmente em áreas de clima semi-árido (Munns 2002). Nestas áreas, as baixas precipitações associadas com a intensa evapo-transpiração contribuem para agravar a salinização do solo (Dantas et al. 2002). O rendimento agrícola é comprometido pela salinidade devido ao déficit hídrico induzido pela alta osmolaridade da solução do solo (Munns 2002), além da toxicidade iônica relacionada com desbalanços nutricionais e desordens metabólicas (Gratan \& Grieve 1999), os quais acarretam a inibição do crescimento.

Além desses distúrbios, o estresse salino pode acarretar o acúmulo excessivo de espécies reativas de oxigênio (EROs) nas células vegetais, especialmente o ânion superóxido $\left(\mathrm{O}_{2}{ }^{-}\right)$, o radical hidroxil $\left(\mathrm{OH}^{\cdot}\right)$ e o peróxido de hidrogênio $\left(\mathrm{H}_{2} \mathrm{O}_{2}\right)$ (Møller et al. 2007). Essas EROs são subprodutos do metabolismo aeróbico e fotossintético e, em concentrações compatíveis com a homeostase redox celular, são componentes de diversas vias de sinalização (Foyer \& Noctor 2003). No entanto, o excesso das EROs causa danos oxidativos em proteínas, lipídeos e ácidos nucléicos, caracterizando o estresse oxidativo secundário (Bem-Amor et al. 2005). Para evitar os danos oxidativos, a concentração das EROs é mantida em níveis não tóxicos por meio de mecanismos antioxidantes enzimáticos e não enzimáticos (Møller et al. 2007).

Dentre os mecanismos enzimáticos envolvidos na detoxificação das EROs, destacam-se as dismutases do superóxido (SODs), as catalases (CATs), as peroxidases do ascorbato (APXs) e as peroxidases de fenóis (POXs). As SODs dismutam o $\mathrm{O}_{2}{ }^{--}$a $\mathrm{H}_{2} \mathrm{O}_{2}$ e se localizam principalmente nas mitocôndrias e nos cloroplastos, compartimentos que geram a maior parte das EROs nas células vegetais (Apel \& Hirt, 2004). $\mathrm{O} \mathrm{H}_{2} \mathrm{O}_{2}$ gerado é então detoxificado pelas CATs, APXs e POXs. As CATs são enzimas peroxissomais e glioxissomais que catalisam a redução direta do $\mathrm{H}_{2} \mathrm{O}_{2}$ a $\mathrm{H}_{2} \mathrm{O}$ e $\mathrm{O}_{2}$ (Yanik and Donaldson 2005), enquanto as APXs eliminam o $\mathrm{H}_{2} \mathrm{O}_{2}$ às expensas do ascorbato e as POXs, reduzindo fenóis (Shigeoka et al. 2002; Cavalcanti et al., 2007). Tanto as APXs quanto as POXs apresentam várias isoformas distribuídas por diversos compartimentos celulares (Shigeoka et al. 2002; Cavalcanti et al., 2007; Passardi et al. 2004). Em conjunto, estas enzimas representam componentes importantes do sistema de proteção oxidativa nas folhas e nas raízes de arroz (Dionisio-Sese \& Tobita 1998), milho (Azevedo-Neto et al. 2006) e feijão caupi (Cavalcanti et al. 2004; Cavalcanti et al. 2007).

As POXs apresentam um caráter bifuncional no metabolismo oxidativo, pois podem utilizar $\mathrm{O}_{2} \mathrm{O}_{2}$ para oxidar vários substratos por meio do seu ciclo catalítico peroxidativo e também podem produzir $\mathrm{OH}^{\cdot}$ a partir do $\mathrm{H}_{2} \mathrm{O}_{2}$ por intermédio do seu ciclo catalítico hidroxílico (Passardi et al. 2004). Assim sendo, as POX de parede celular podem viabilizar o alongamento celular devido à produção de $\mathrm{OH}^{\cdot}$ e à clivagem não-enzimática dos polissacarídeos de ligação cruzada (Liszkay et al. 2004). Por outro lado, estas enzimas também podem restringir o crescimento celular por meio do espessamento da parede celular em decorrência da eliminação do $\mathrm{H}_{2} \mathrm{O}_{2}$ associada à polimerização dos precursores da lignina (Passardi et al. 2004). Como conseqüência, as POX de parede celular podem estar envolvidas na regulação do crescimento celular envolvendo o metabolismo do $\mathrm{H}_{2} \mathrm{O}_{2}$.

Em um trabalho anterior, o padrão de respostas antioxidativas nas folhas de feijão caupi exposto ao estresse salino se mostrou diferente daquele verificado nas raízes (Cavalcanti et al. 2007). Além disso, os mecanismos antioxidantes enzimáticos ativados em feijão caupi sob salinidade parecem estar associados à inibição do crescimento. Contudo, pouco ainda é conhecido sobre o envolvimento do sistema enzimático removedor das EROs na regulação do crescimento em plantas sob estresse salino. Neste sentido, o presente estudo teve como objetivo a avaliação integrada de indicadores de crescimento, toxicidade iônica, estado hídrico, estresse oxidativo e proteção antioxidativa nas raízes das cultivares Pérola e Pitiúba de feijão caupi expostas à salinidade. Estas cultivares foram escolhidas por apresentarem respostas contrastantes ao estresse salino durante a germinação das sementes, sendo a cultivar Pérola mais sensível que a Pitiúba (Freitas 2006). Desta maneira, almejou-se comparar as respostas fisiológicas fornecidas por estas cultivares ao estresse salino durante o crescimento inicial, além de verificar relações entre a inibição do crescimento radicular, o estresse oxidativo secundário e a atividade protetora das enzimas antioxidativas SOD, APX, CAT e POX.

\section{Material e métodos}

\section{Material vegetal e tratamento salino}

As sementes das cultivares Pérola e Pitiúba de feijão caupi [Vigna unguiculata L. Walp] foram fornecidas pelo Departamento de Fitotecnia da Universidade Federal do Ceará. Essas sementes foram desinfetadas com hipoclorito de sódio $0,1 \%(\mathrm{~m} / \mathrm{v})$ por $5 \mathrm{~min}$ sob agitação eventual, lavadas com água deionizada e germinadas em papel para teste de germinação (dimensões $28 \times 38 \mathrm{~cm}$ ) umedecido com água deionizada $\left(2,5 \mathrm{~mL} \mathrm{~g}^{-1}\right.$ papel). Os rolos de papel foram cobertos por sacos plásticos desinfetados com etanol $70 \%$ $(\mathrm{v} / \mathrm{v})$ e as sementes foram mantidas em câmara de crescimento sob fotoperíodo de $12 \mathrm{~h}$, irradiância de $240 \mu \mathrm{mol} \mathrm{m}{ }^{-2}$ $\mathrm{s}^{-1}$, temperatura de $27 \pm 2^{\circ} \mathrm{C}$, umidade relativa de $80 \pm 10 \%$.

Quatro dias após o semeio (DAS) as plântulas foram submetidas ao tratamento salino pela troca do papel de germinação por outro umedecido com $\mathrm{NaCl}$ nas concentrações de 0 (controle), 25, 50, 75 e 100 mM. As plântulas foram mantidas nas mesmas condições experimentais por mais seis dias. Em seguida, as raízes foram destacadas da parte aérea e uma parte do material foi utilizada para determinação do comprimento radicular, do conteúdo relativo 
de água, do conteúdo $\mathrm{Na}^{+}$e $\mathrm{K}^{+}$e do dano de membranas. A parte restante do material foi congelada em nitrogênio líquido e armazenada a $-80^{\circ} \mathrm{C}$ para determinações bioquímicas posteriores.

\section{Determinações realizadas}

O comprimento radicular foi mensurado com auxílio de um paquímetro e o conteúdo relativo de água (C.R.A.) foi determinado conforme Irigoyen et al. (1992). O conteúdo de $\mathrm{Na}^{+}$e $\mathrm{K}^{+}$dos tecidos radiculares foi determinado por fotometria de chama e dano em membranas foi estimado pelo vazamento de eletrólitos segundo Cavalcanti et al. (2004) e pela peroxidação de lipídios, baseada na concentração de substâncias reativas ao ácido tiobarbitúrico (TBARS), de acordo com Heath \& Packer (1968).

Os coramentos histoquímicos foram realizados segundo Zhou et al. (2007). Para avaliar a viabilidade celular, segmentos radiculares foram lavados com $\mathrm{CaCl}_{2} 0,5 \mathrm{mM}$ (pH $4,5)$, secados suavemente em papel de filtro e imersos em azul de Evans 0,025\% (m/v) em $\mathrm{CaCl}_{2} 0,1 \mathrm{mM}$ (pH 5,6) a $10^{\circ} \mathrm{C}$ por $24 \mathrm{~h}$. Para detectar a peroxidação de lipídios, os segmentos radiculares foram imersos em reagente de Shiff à temperatura ambiente por $60 \mathrm{~min}$, enxaguados em bissulfito de potássio $\left(\mathrm{K}_{2} \mathrm{~S}_{2} \mathrm{O}_{5}\right)$ 0,5\% (m/v) em $\mathrm{HCl} \mathrm{0,05} \mathrm{M}$ e lavados com água destilada. Após os coramentos, estes segmentos foram fotografados em uma lupa acoplada à câmera digital.

Para extração de proteínas, amostras de tecidos congelados (100 mg) foram maceradas em nitrogênio líquido e extraídas com tampão fosfato de potássio $50 \mathrm{mM}(\mathrm{pH} 7,0)$, contendo ácido L-ascórbico $1 \mathrm{mM}$ e ácido etilenodiaminotetracético (EDTA) 0,1 mM. Os extratos foram centrifugados a $13.000 \mathrm{x} \mathrm{a} 4^{\circ} \mathrm{C}$ por 20 min e o sobrenadante foi utilizado na determinação das proteínas solúveis conforme Bradford (1976) e das atividades enzimáticas.

A atividade da dismutase do superóxido (SOD) foi determinada pela inibição da foto-redução do cloreto de nitrotetrazólio azul (NBT) conforme Beauchamp \& Fridovich (1971). Alíquotas de $0,1 \mathrm{~mL}$ do extrato protéico foram transferidas para tubos de ensaio contendo meio de reação composto por tampão fosfato de potássio $50 \mathrm{mM}$ (pH 7,8), EDTA 0,1 mM, L-metionina $13 \mathrm{mM}$ e NBT 75 $\mu \mathrm{M}$. A reação foi iniciada pela adição de riboflavina $2 \mu \mathrm{M}$, seguido da iluminação do meio de reação com lâmpadas fluorescentes de $30 \mathrm{~W}$ em caixa fechada. Após $5 \mathrm{~min}$, a reação foi interrompida pelo desligamento das luzes e as leituras foram realizadas a $560 \mathrm{~nm}$. Uma unidade de atividade (UA) foi considerada como a quantidade de enzima requerida para inibir 50\% da foto-redução do NBT em comparação com o meio de reação sem o extrato protéico. A atividade de SOD foi expressa em UA g ${ }^{-1} \mathrm{MS}$ min $^{-1}$.

Para a determinação da atividade de catalase (CAT), foi determinado o consumo de $\mathrm{H}_{2} \mathrm{O}_{2}$ baseado no decréscimo da absorbância a $240 \mathrm{~nm}$, conforme Sudhakar et al. (2001). Alíquotas de $0,05 \mathrm{~mL}$ do extrato foram adicionadas a 2,95 $\mathrm{mL}$ de meio de reação constituído de tampão fosfato de po- tássio $50 \mathrm{mM}(\mathrm{pH} 7,0)$ a $30^{\circ} \mathrm{C}$, acrescido de $\mathrm{H}_{2} \mathrm{O}_{2} 20 \mathrm{mM}$. A atividade de CAT foi expressa em nmol $\mathrm{H}_{2} \mathrm{O}_{2} \mathrm{~g}^{-1} \mathrm{MS} \mathrm{min}{ }^{-1}$.

Para mensurar a atividade da peroxidase de ascorbato (APX), o consumo de ascorbato foi detectado pelo decréscimo da absorbância a $290 \mathrm{~nm}$, segundo Nakano \& Asada (1981). Alíquotas de 0,1 mL do extrato foram transferidas para tubos de ensaio contendo $2,7 \mathrm{~mL}$ de tampão fosfato de potássio $50 \mathrm{mM}$ (pH 6,0) e L-ascorbato $0,8 \mathrm{mM}$. A reação foi iniciada pela adição de $\mathrm{H}_{2} \mathrm{O}_{2} 2 \mathrm{mM}$ e a atividade enzimática foi expressa em $\mu \mathrm{mol}$ ascorbato $\mathrm{g}^{-1} \mathrm{MS} \mathrm{min}^{-1}$.

A atividade da peroxidase de fenóis (POX) foi determinada conforme Kar \& Mishra (1976). Alíquotas de 0,02 mL do extrato foram transferidas para tubos de ensaio contendo $4,9 \mathrm{~mL}$ de tampão fosfato de potássio $25 \mathrm{mM}$ (pH 6,8), ácido

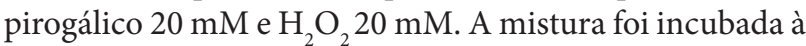
temperatura ambiente por 1 min e a reação foi interrompida pela adição de $0,5 \mathrm{~mL}$ de $\mathrm{H}_{2} \mathrm{SO}_{4} 0,5 \%$ (v/v). Em seguida, as leituras foram realizadas a $420 \mathrm{~nm}$ e a atividade de POX foi expressa em nmol purpurogalina $\mathrm{g}^{-1} \mathrm{MS} \mathrm{min}^{-1}$.

\section{Delineamento estatístico e análise dos dados}

$\mathrm{O}$ experimento foi realizado em delineamento inteiramente casualizado com os tratamentos dispostos em fatorial $2 \times 5$, incluindo duas cultivares de feijão caupi (Pérola e Pitiúba) e cinco concentrações de $\mathrm{NaCl}(0,25,50,75$ e 100 $\mathrm{mM}$ ), com três repetições por tratamento. Os dados foram submetidos ao teste $\mathrm{F}$ a 0,05 de probabilidade e as médias foram comparadas pelo teste de Tukey em mesmo nível de significância.

\section{Resultados}

No presente estudo, as raízes das cultivares Pérola e Pitiúba de feijão caupi expostas a concentrações crescentes de $\mathrm{NaCl}$ durante dois dias apresentaram respostas fisiológicas semelhantes quanto aos indicadores de estado hídrico, toxicidade iônica e danos em membranas. No entanto, as raízes destas cultivares apresentaram respostas distintas aos tratamentos salinos considerando o indicador de crescimento e a atividade das enzimas antioxidativas.

$\mathrm{O}$ aumento da concentração externa de $\mathrm{NaCl}$ reduziu progressivamente o comprimento radicular em ambas as cultivares, mas a Pitiúba foi mais afetada. De fato, a cultivar Pitiúba sofreu redução no comprimento radicular da ordem de $56 \%$ e a cultivar Pérola, de apenas 25\%, sob a concentração de sal mais elevada $(\mathrm{NaCl} 100 \mathrm{mM})$, em relação aos respectivos controles (Fig. 1A). Apesar disso, os tratamentos salinos não afetaram o estado de hídrico dos tecidos radiculares nas duas cultivares, considerando a manutenção do CRA (Fig. 1B). Porém, a razão $\mathrm{K}^{+} /$ $\mathrm{Na}^{+}$nestes tecidos foi diminuída conforme a elevação da concentração externa de $\mathrm{NaCl}$ para as cultivares Pérola e Pitiúba. Em comparação com os respectivos controles, a razão $\mathrm{K}^{+} / \mathrm{Na}^{+}$foi diminuída em aproximadamente $80 \%$ sob $\mathrm{NaCl} 100 \mathrm{mM}$ (Fig. 1C). 


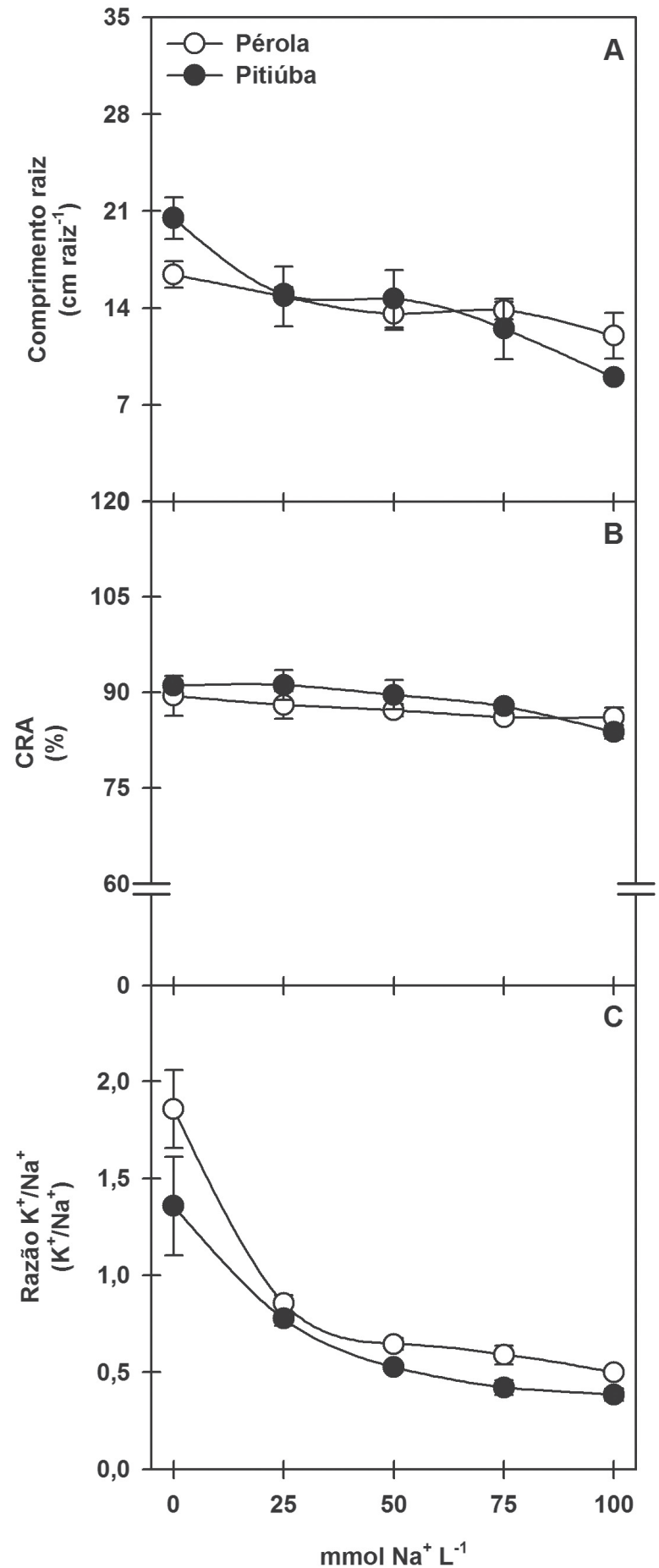

Figura 1. Comprimento radicular (A), conteúdo relativo de água (B) e relação $\mathrm{K}^{+} / \mathrm{Na}^{+}(\mathrm{C})$ em raízes de plântulas de feijão caupi, cultivares Pérola e Pitiúba, tratadas com NaCl 0, 25, 50, 75 e $100 \mathrm{mM}$ por seis dias sob condições controladas. Os resultados foram analisados por ANOVA e as médias foram comparadas pelo teste de Tukey $(\mathrm{p} \leq 0,05)$.
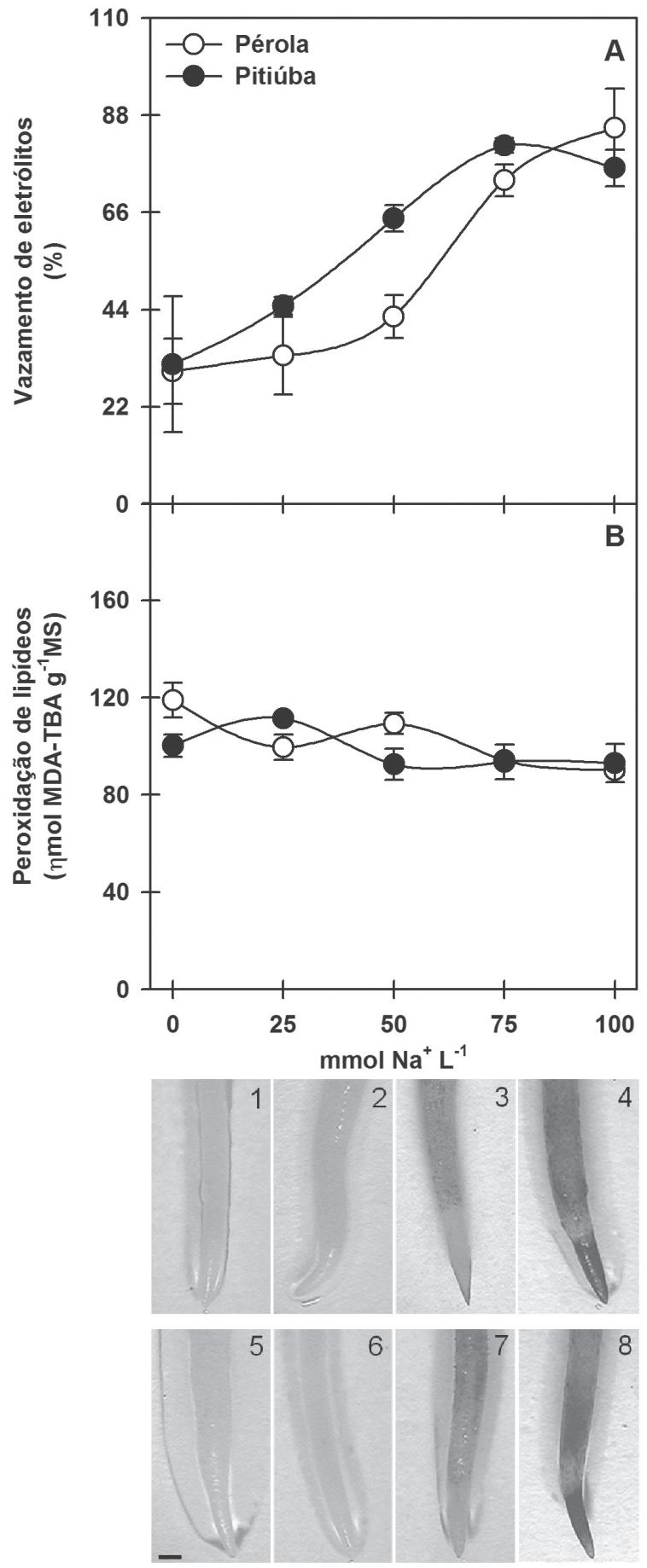

Figura 2. Vazamento de eletrólitos (A) e peroxidação de lipídeos (B) em raízes de duas cultivares de feijão caupi expostas $0,25,50,75$ e $100 \mathrm{mM}$ de $\mathrm{NaCl}$ durante seis dias. Os valores são médias de três repetições \pm desvio padrão. Raízes de Pérola (1, 2, 3 e 4) e Pitiúba (5, 6, 7 e 8) submetidas aos tratamentos controle $(0 \mathrm{mM}$ de $\mathrm{NaCl}-1,3,5,6)$ e $100 \mathrm{mM}$ de $\mathrm{NaCl}(2,4,6,8)$ (C). Coloração histoquímica in situ dos danos em membranas $(1,2,5$ e 6$)$ e peroxidação de lipídeos (3, 4, 7 e 8). 
Os tratamentos salinos ocasionaram o aumento dos danos em membranas, baseados no vazamento de eletrólitos, nos tecidos radiculares das cultivares Pérola e Pitiúba. $\mathrm{Na}$ concentração de sal mais elevada, o vazamento de eletrólitos nestes tecidos apresentou aumento de cerca de três vezes em relação aos respectivos controles (Fig. 2A). No entanto, não houve alteração na peroxidação de lipídios nos tecidos radiculares em ambas as cultivares (Fig. 2B). Este resultado foi confirmado pelo coramento histoquímico in situ utilizando o reagente de Shiff para detecção de aldeídos (Fig. 2C), os quais são subprodutos da peroxidação lipídica. Embora não tenha sido detectado aumento da peroxidação lipídica, o coramento in situ dos tecidos radiculares com o reagente de Evans demonstrou a ocorrência de morte celular induzida pela salinidade nas duas cultivares, principalmente na região apical (Fig. 2C).

A atividade das enzimas antioxidativas foi modulada diferencialmente pelo $\mathrm{NaCl}$ nas raízes das plântulas de feijão caupi. Embora a atividade da SOD não tenha sido alterada pelos tratamentos salinos na Pérola, ela foi reduzida em 20\% na Pitiúba sob $\mathrm{NaCl}$ 25; 50 e 75 mM, em comparação com o respectivo controle (Fig. 3A). O aumento da concentração externa de $\mathrm{NaCl}$ diminuiu progressivamente a atividade de APX e CAT em ambas as cultivares, mas a Pitiúba apresentou resposta mais proeminente. $\mathrm{Na}$ presença de $\mathrm{NaCl} 100$ $\mathrm{mM}$, a atividade de APX decresceu apenas $10 \%$ na Pérola e até $50 \%$ na Pitiúba, considerando os respectivos controles (Fig. 3B). Além disso, a atividade de CAT foi reduzida em $10 \%$ na Pérola a partir de $\mathrm{NaCl} 50 \mathrm{mM}$ e foi diminuída em até $50 \%$ na Pitiúba sob $\mathrm{NaCl} 100 \mathrm{mM}$, em comparação com os respectivos controles (Fig. 3C).

Ao contrário da tendência verificada para a atividade das enzimas SOD, APX e CAT, a atividade da POX foi intensamente estimulada pela salinidade nas raízes das plântulas de feijão caupi. Na cultivar Pérola, a atividade da POX foi aumentada em $46 \%$ a partir de $\mathrm{NaCl} 75 \mathrm{mM}$, enquanto na Pitiúba foi incrementada em apenas $10 \%$ sob $\mathrm{NaCl} 25,50$ e $75 \mathrm{mM}$ e em até $46 \%$ na presença de $\mathrm{NaCl} 100 \mathrm{mM}$ (Fig. 3D).

\section{Discussão}

Neste trabalho, as cultivares Pérola e Pitiúba de feijão caupi foram comparadas quanto às respostas fisiológicas fornecidas pelas raízes sob salinidade durante o crescimento inicial. Além disso, foi conduzida uma avaliação integrada considerando a inibição do crescimento radicular, os efeitos primários do estresse salino, a indução de estresse oxidativo secundário e a atividade protetora de enzimas antioxidativas. As raízes foram utilizadas como modelo experimental por manterem contato direto com a salinidade, consistindo nos primeiros órgãos a serem afetados (Di Baccio et al. 2004).

A inibição do crescimento radicular devido ao estresse salino tem sido amplamente notificada, especialmente em plantas cultivadas, como o sorgo (Wahid et al. 1998), o feijão comum (Dash \& Panda 2001), a mamona (Pinheiro et al. 2008), o cajueiro (Ferreira-Silva et al. 2008) e o pinhão-manso (Silva et al. 2009). No presente estudo, a redução do comprimento radicular foi utilizada com um indicador da inibição do crescimento em plântulas de feijão caupi expostas à salinidade. $\mathrm{O}$ crescimento radicular pode ser restringido tanto pelo déficit hídrico induzido pela osmolaridade elevada da solução quanto pela toxicidade iônica, envolvendo danos metabólicos e fisiológicos (Munns \& Tester 2008).

Considerando que concentrações externas crescentes de $\mathrm{NaCl}$ reduziram progressivamente a razão $\mathrm{K}^{+} / \mathrm{Na}^{+}$, mas não alteraram o estado hídrico dos tecidos radiculares de feijão caupi, a inibição do crescimento parece estar mais relacionada à toxicidade iônica que ao déficit hídrico induzido pela salinidade. A razão $\mathrm{K}^{+} / \mathrm{Na}^{+}$tem sido utilizada como indicador de toxicidade iônica, uma vez que valores abaixo de 1,0 indicam um balanço desfavorável para a aquisição e a utilização do $\mathrm{K}^{+}$, baseado na competição entre $\mathrm{K}^{+} \mathrm{e} \mathrm{Na}^{+}$por sítios de ligação em transportadores de membrana e enzimas dependentes de $\mathrm{K}^{+}$(Maathuis \& Amtmann 1999). Desta maneira, a concentração externa de $\mathrm{NaCl}$ igual ou superior a $25 \mathrm{mM}$ pode induzir toxicidade iônica nos tecidos radiculares de feijão caupi no decorrer do tempo de exposição.

A inibição do crescimento e a toxicidade iônica podem ser relacionadas com os danos em membranas estimados para as raízes de feijão caupi sob estresse salino. O vazamento de eletrólitos foi aumentado gradualmente de acordo com o incremento da concentração externa de $\mathrm{NaCl}$, indicando o rompimento de membranas celulares. Este resultado foi confirmado pela coloração de segmentos radiculares com Azul de Evans, o qual é um corante vital e cora totalmente células mortas (Ruzin 1999). Levando em conta que a coloração foi mais intensa nos ápices radiculares, a inibição do crescimento em feijão caupi deve envolver morte celular induzida pela salinidade nas regiões de crescimento. A morte celular pode ser desencadeada pela toxicidade iônica, já que o excesso de $\mathrm{Na}^{+}$externo pode deslocar $\mathrm{o} \mathrm{Ca}^{+2}$ estrutural da superfície celular, acarretando a desestabilização da membrana plasmática e o conseqüente vazamento de componentes citoplasmáticos (Cramer et al. 1985; Mengel \& Kirkby 2001).

Os danos em membranas estimados para as raízes de feijão caupi pelo vazamento de eletrólitos não foram corroborados pela peroxidação de lipídios. De fato, a peroxidação de lipídios baseada na concentração de TBARS não foi alterada com o aumento da concentração externa de $\mathrm{NaCl}$. A coloração de segmentos radiculares com reagente de Shiff confirmou este resultado, já que este reagente evidencia aldeídos, os quais são subprodutos da peroxidação de lipídios (Yamamoto et al. 2001). Considerando que a concentração de TBARS tem sido usada como indicador de danos oxidativos (Dionisio-Sese \& Tobita 1998; Sairam \& Srivastava 2002; Bandeoglu et al. 2004), é possível que a salinidade não tenha acarretado o estresse oxidativo secun- 


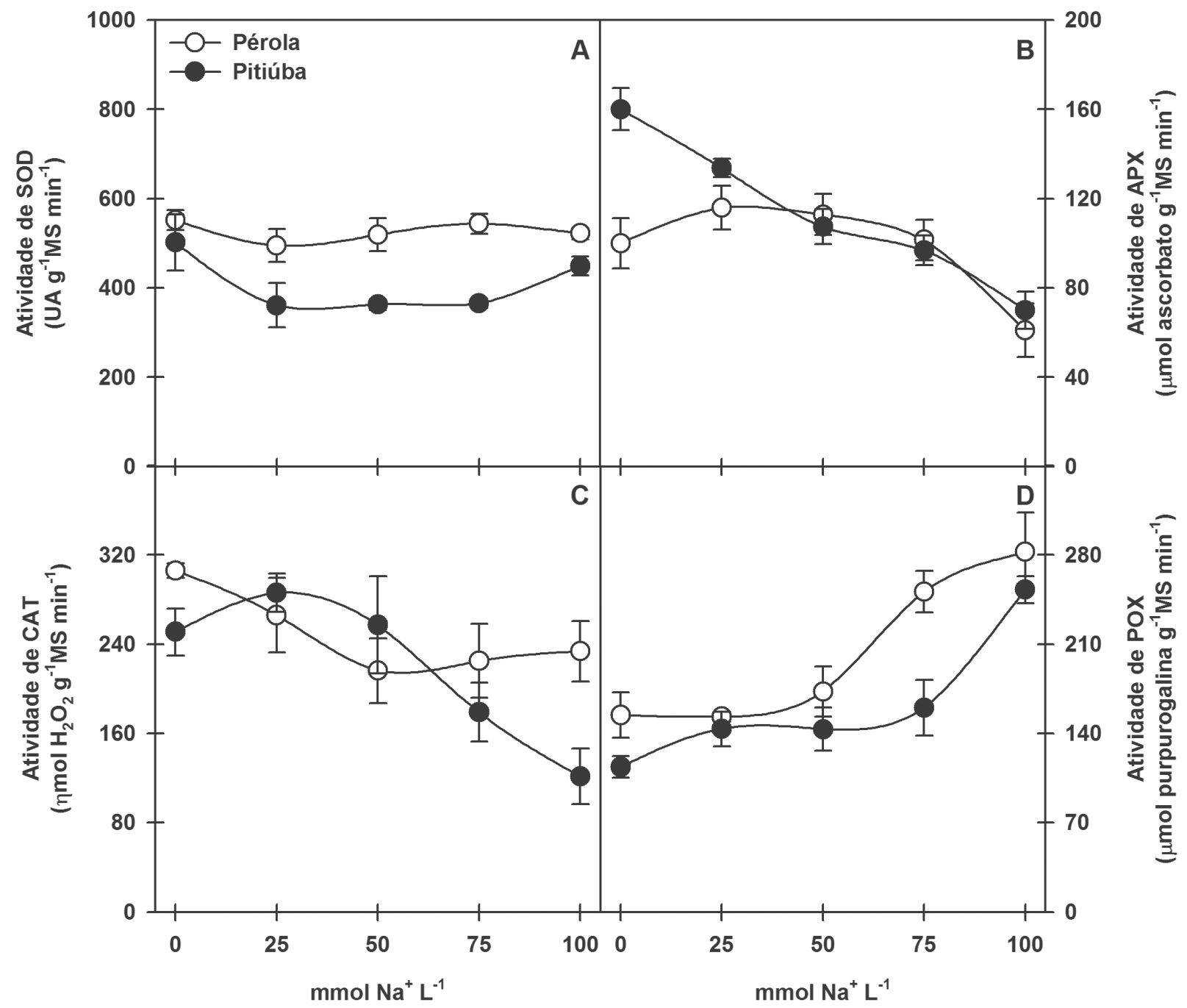

Figura 3. Atividade da dismutase de superóxido (SOD) (A), peroxidase do ascorbato (APX) (B), catalase (CAT) (C) e peroxidase de fenóis (POX) (D) em raízes de plântulas de feijão caupi cultivares Pérola e Pitiúba, tratadas com $\mathrm{NaCl}$ 0, 25, 50, 75 e $100 \mathrm{mM}$ por seis dias sob condições controladas. Os resultados foram analisados por ANOVA e as médias foram comparadas pelo teste de Tukey $(\mathrm{p} \leq 0,05)$.

dário em raízes de feijão caupi. Assim sendo, esta espécie deve apresentar mecanismos eficientes para a renovação dos lipídios de membrana afetados e/ou para a remoção das EROs produzidas.

Diversos estudos têm demonstrado o papel dos mecanismos antioxidantes enzimáticos na proteção contra o estresse oxidativo secundário induzido pela salinidade (Bandeoglu et al. 2004; Bem Amor et al. 2005; Rubio et al. 2009). Em raízes de arroz (Lin \& Kao 2001), tomate (Mittova et al. 2004), milho (Azevedo-Neto et al. 2006) e feijão caupi (Cavalcanti et al. 2007), o aumento da atividade de enzimas como SOD, APX, CAT e POX está associado com a manutenção dos níveis de peroxidação de lipídios sob estresse salino. No presente trabalho, a manutenção da peroxidação de lipídios nas raízes de plântulas de feijão caupi sob estresse salino foi associada à diminuição da atividade de SOD, APX e CAT e ao incremento intenso da atividade de POX, sugerindo que esta última apresenta algum papel na proteção oxidativa.
A remoção enzimática do $\mathrm{H}_{2} \mathrm{O}_{2}$ por meio do ciclo catalítico peroxidativo da POX pode ocorrer de forma simultânea com a biossíntese de lignina no apoplasto, resultando no espessamento da parede celular (Passardi et al. 2004). Neste sentido, a remoção do $\mathrm{H}_{2} \mathrm{O}_{2}$ pela $\mathrm{POX}$ pode funcionar como estratégia para evitar o estresse oxidativo secundário, restringindo o crescimento celular como conseqüência. Em um trabalho anterior, a inibição do crescimento radicular em feijão caupi sob tratamento salino foi acompanhada pelo aumento intenso da atividade de POX, assim como a retomada do crescimento sob tratamento de recuperação ocorreu de forma simultânea com a redução da atividade desta enzima (Cavalcanti et al. 2007). Estes resultados são corroborados pelo presente estudo, no qual a redução do comprimento radicular está associada à manutenção da peroxidação de lipídios e ao aumento da atividade de POX. Assim, sugere-se que a inibição do crescimento imposta pela salinidade pode estar relacionada com o papel da POX na remoção do $\mathrm{H}_{2} \mathrm{O}_{2}$. 
A despeito das cultivares Pérola e Pitiúba terem apresentado respostas fisiológicas distintas à salinidade durante a germinação das sementes (Freitas 2006), estas mostraram poucas diferenças de acordo com os indicadores avaliados neste estudo durante o desenvolvimento inicial. De fato, a cultivar Pérola apresentou, proporcionalmente, menor inibição do crescimento radicular, associada à menor inibição da atividade de APX e CAT e maior indução da atividade de POX. Assim sendo, é possível que a cultivar Pérola seja mais susceptível ao estresse salino no decorrer da germinação das sementes (Freitas 2006), superando esta susceptibilidade durante o estabelecimento das plântulas. Estes resultados indicam que a avaliação da resistência ao estresse salino deve ser conduzida com cautela, levando em conta o estádio fisiológico das plantas (Perez-Prat et al. 1994; Kartashov et al. 2008).

Considerando todos os resultados apresentados neste trabalho, a redução no elongamento das raízes de feijão caupi sob salinidade pode ser atribuída, pelo menos em parte, a uma sincronia entre o aumento da atividade de peroxidase de fenóis e redução nas atividades de catalase e peroxidase de ascorbato. Além disso, a peroxidação de lipídios pode ter sido evitada pelo aumento da atividade de POX, contribuindo para a remoção de EROs. No entanto, mais estudos se fazem necessários para esclarecer os mecanismos que desencadeiam a morte celular induzida pela salinidade, assim como o papel da atividade de POX na inibição do crescimento radicular em feijão caupi.

\section{Agradecimentos}

Os autores agradecem à Fundação Cearense de Apoio ao Desenvolvimento e Tecnológico (FUNCAP) e ao Conselho Nacional de Desenvolvimento Científico e Tecnológico (CNPq) pelo financiamento de projetos e bolsas de auxílio que contribuíram para o desenvolvimento das pesquisas.

\section{Referências}

Apel, K. \& Hirt, H. 2004. Reactive oxygen species: metabolism, oxidative stress, and signal transduction. Annual Review of Plant Biology 55: 373-399.

Azevedo-Neto, A.D.D.; Prisco, J.T.; Enéas-Filho, J.; Abreu, C.E.B. \& GomesFilho, E. 2006. Effect of salt stress on antioxidative enzymes and lipid peroxidation in leaves and roots of salt-tolerant and salt-sensitive maize genotypes. Environmental and Experimental Botany 56: 87-94.

Bandeoglu, E.; Eyidogan, F.; Yücel, M. \& Öktem, H.A. 2004. Antioxidant responses of shoots and roots of lentil to $\mathrm{NaCl}$-salinity stress. Plant Growth Regulation 42: 69-77.

Beauchamp, C. \& Fridovich, I. 1971. Superoxide dismutase - improved assays and an assay applicable to acrylamide gels. Analytical Biochemistry 44: 276-287.

Ben Amor, N.; Ben Hamed, K.; Debeza, A.; Grignonb, C. \& Abdelly, C. 2005. Physiological and antioxidant responses of the perennial halophyte Crithmum maritimum to salinity. Plant Science 168: 889-899.

Bradford, M.M. 1976. A rapid and sensitive method for quantitation of microgram quantities of protein utilizing the principle of protein-dyebinding. Analytical Biochemistry 72: 248-254.
Cavalcanti, F.R.; Lima, J.P.M.S.; Ferreira-Silva, S.L.; Viégas, R.A. \& Silveira, J.A.G. 2007. Roots and leaves display contrasting oxidative response during salt stress and recovery in cowpea. Journal of Plant Physiology 164: 591-600.

Cavalcanti, F.R.; Oliveira, J.T.A.; Martins-Miranda, A.S.; Viégas, R.A. \& Silveira, J.A.G. 2004. Superoxide dismutase, catalase and peroxidase activities do not confer protection against oxidative damage in saltstressed cowpea leaves. New Phytologist 163: 563-571.

Cramer, G.R.; Lauchli, A. \& Polito, V.S. 1985. Displacement of $\mathrm{Ca}^{2+}$ by $\mathrm{Na}^{+}$ from the Plasmalemma of root-cells - a primary response to salt stress. Plant Physiology 79: 207-211.

Dantas, J.P.; Marinho, F.J.L.; Ferreira, M.M.M.; Amorim, M.S.N.; Andrade, S.I.O. \& Sales, A.L. 2002. Avaliação de genótipos de feijão-de-corda sob salinidade. Revista Brasileira de Engenharia Agrícola e Ambiental 6: 425-430.

Dash, M. \& Panda, S.K. 2001. Salt stress induced changes in growth and enzyme activities in germinating Phaseolus mungo seeds. Biologia Plantarum 44: 587-589.

Di Baccio, D.; Navari-Izzo, F. \& Izzo, R. 2004. Seawater irrigation: antioxidant defence responses in leaves and roots of a sunflower (Helianthus annuus L.) ecotype. Journal of Plant Physiology 161: 1359-1366.

Dionisio-Sese, M.L. \& Tobita, S. 1998. Antioxidant responses of rice seedlings to salinity stress. Plant Science 135: 1-9.

Ferreira-Silva, S.L.; Silveira, J.A.G.; Voigt, E.L.; Lucilene, S.P.S. \& Viégas, R.A. 2008. Changes in physiological indicators associated with salt tolerance in two contrasting cashew rootstocks. Brazilian Journal of Plant Physiology 20: 51-59.

Foyer, C.H. \& Noctor, G. 2003. Redox sensing and signaling associated with reactive oxygen in chloroplasts, peroxisomes and mitochondria. Physiologia Plantarum 119: 355-364.

Freitas, J.B.S. 2006. Respostas fisiológicas ao estresse salino de duas cultivares de feijão caupi. Tese de Doutorado. Universidade Federal do Ceará, Fortaleza.

Grattan, S.R. \& Grieve, C.M. 1999. Salinity mineral nutrient relations in horticultural crops. Scientia Horticulturae 78: 127-157.

Heath, R.L. \& Packer, L. 1968. Photoperoxidation in isolated chloroplasts .2. Role of electron transfer. Archives of Biochemistry and Biophysics 125: 850-857.

Irigoyen, J.J.; Emerich, D.W. \& Sanchez-Diaz, M. 1992. Water-stress induced changes in concentrations of proline and total soluble sugars in nodulated alfalfa (Medicago sativa) plants. Physiologia Plantarum 84: $55-60$.

Kar, M. \& Mishra, D. 1976. Catalase, peroxidase, and polyphenoloxidase activities during rice leaf senescence. Plant Physiology 57: 315-319.

Kartashov, A.V.; Radyukina, N.L.; Ivanov, Y.V.; Pashkovskii, P.P.; Shevyakova, N.I. \& Kuznetsov, V.V. 2008. Role of antioxidant systems in wild plant adaptation to salt stress. Russian Journal of Plant Physiology 55: 463-468.

Liszkay, A.; van der Zalm, E. \& Schopfer, P. 2004. Production of reactive oxygen intermediates $\left(\mathrm{O}^{-2}\right.$ (center dot-), $\mathrm{H}_{2} \mathrm{O}_{2}$, and $(\mathrm{OH})-\mathrm{O}$-center dot) by maize roots and their role in wall loosening and elongation growth. Plant Physiology 136: 3114-3123.

Lin, C.C. \& Kao, C.H. 2001. Cell wall peroxidase activity, hydrogen peroxide level and $\mathrm{NaCl}$-inhibited root growth of rice seedlings. Plant and Soil 230: 135-143.

Maathuis, F.J.M. \& Amtmann, A. 1999. $\mathrm{K}^{+}$nutrition and $\mathrm{Na}^{+}$toxicity: the basis of cellular $\mathrm{K}^{+} / \mathrm{Na}^{+}$ratios. Annals of Botany 84: 123-133.

Mittova, V.; Guy, M.; Tal, M. \& Volokita, M. 2004. Salinity up-regulates the antioxidative system in root mitochondria and peroxisomes of the wild salt-tolerant tomato species Lycopersicon pennellii. Journal of Experimental Botany 55: 1105-1113.

Mengel, K. \& Kirkby, E.A. 2001. Principles of plant nutrition. Netherlands, Kluwer Academic Publishers.

Møller, I.M.; Jensen, P.E. \& Hansson, A. 2007. Oxidative modifications to cellular components in plants. Annual Review of Plant Biology 58: $459-481$.

Munns, R. \& Tester, M. 2008. Mechanisms of salinity tolerance. Annual Review of Plant Biology 59: 651-681. 
Munns, R. 2002. Comparative physiology of salt and water stress. Plant, Cell and Environment 25: 239-250.

Nakano, Y. \& Asada, K. 1981. Hydrogen-peroxide is scavenged by ascorbate-specific peroxidase in spinach-chloroplasts. Plant Cell Physiology 22: 867-880.

Passardi, F.; Penel, C. \& Dunand, C. 2004. Performing the paradoxical: how plant peroxidases modify the cell wall. Trends in Plant Science 9: 534-540.

Perez-Prat, E.; Narasimham, M.L.; Niu, X.; Botella, M.A.; Bressan, R.A.; Valpuesta, V.; Hasegawa, P.M. \& Binzel, M.L. 1994. Growth cycle stage-dependent $\mathrm{NaCl}$ induction of plasma membrane $\mathrm{H}^{+}$-ATPase mRNA accumulation in de-adapted tobacco cells. Plant, Cell \& Environment 17: 327-333.

Pinheiro, H.A.; Silva, J.V.; Endres, L.; Ferreira, V.M.; Câmara, C.A.; Cabral, F.F.; Oliveira, J.F.; Carvalho, L.W.T.; Santos, J.M. \& Santos-Filho, B.G. 2008. Leaf gas exchange, chloroplastic pigments and dry matter accumulation in castor bean (Ricinus communis L.) seedlings subjected to salt stress conditions. Industrial Crops and Products 27: 385-392.

Rubio, M.C.; Bustos-Sanmamed, P.; Clemente, M.R. \& Becana, M. 2009. Effects of salt stress on the expression of antioxidant genes and proteins in the model legume Lotus japonicus. New Phytologist 181: 851-859.

Ruzin, S.E. 1999. Microtechnique and microscopy. New York, University Press Inc.

Sairam, R.K. \& Srivastava, G.C. 2002. Changes in antioxidant activity in sub-cellular fractions of tolerant and susceptible wheat genotypes in response to long term salt stress. Plant Science 162: 897-904.
Shigeoka, S.; Ishikawa, T.; Tamoi, M.; Miyagawa, Y.; Takeda, T.; Yabuta, Y. \& Yoshimura, K. 2002. Regulation and function of ascorbate peroxidase isoenzymes. Journal of Experimental Botany 53: 1305-1319.

Silva, E.N.; Silveira, J.A.G.; Rodrigues, C.R.F.; Dutra, A.T.B. \& Aragão, R.M. 2009. Acúmulo de íons e crescimento de pinhão-manso sob diferentes níveis de salinidade. Revista de Ciência Agronômica 40: $240-246$.

Sudhakar, C.; Lakshmi, A. \& Giridarakumar, S. 2001. Changes in the antioxidant enzyme efficacy in two high yielding genotypes of mulberry (Morus alba L.) under $\mathrm{NaCl}$ salinity. Plant Science 161: 613-619.

Wahid, A.; Javed, I-ul-H.; Ali, I.; Baig, A. \& Rasul, E. 1998. Short term incubation of sorghum caryopses in sodium chloride levels. Changes is some pre- and post-germination physiological parameters. Plant Science 139: 223-232.

Yamamoto, Y.; Kobayashi, Y. \& Matsumoto, H. 2001. Lipid peroxidation is an early symptom triggered by aluminum, but not the primary cause of elongation inhibition in pea roots. Plant Physiology 125: 199-208.

Yanik, T.; Donaldson, R.P. 2005. A protective association between catalase and isocitrate lyase in peroxisomes. Archives of Biochemistry and Biophysics 435: 243-252.

Zhou, Z.S.; Huang, S.Q.; Yang, Z.M. 2007. Metabolic adaptations to mercury-induced oxidative stress in roots of Medicago sativa $\mathrm{L}$. Chemosphere 101: 1-9. 